\title{
RANS Model Calibration Using Stochastic Optimization for Accuracy Improvement of Urban Airflow CFD Modeling
}

\author{
Mohammadreza Shirzadia1, Parham A. Mirzaei ${ }^{\mathrm{b}}$, Yoshihide Tominaga ${ }^{\mathrm{a}}$ \\ a Wind and Fluid Engineering Research Center, Niigata Institute of Technology, \\ Kashiwazaki, Japan \\ ${ }^{\mathrm{b}}$ Architecture and Built Environment Department, University of Nottingham, Nottingham, \\ UK
}

\begin{abstract}
In this study, a systematic calibration methodology is proposed for enhancing the accuracy of urban airflow simulations using computational fluid dynamics (CFD) models based on the Reynolds-averaged Navier-Stokes (RANS) equations. In the calibration process, high-quality data from different sources are used to define the validation metrics, which are then utilized as the objective function in a stochastic optimization solver to find optimal values for closure coefficients of the RANS turbulence model. The proposed calibration method is applied to three different urban case studies, including an unstable atmospheric boundary layer ( $A B L)$ around a high-rise building, a sheltered cross-ventilated low-rise building, and a group of low-rise buildings located in a highly packed urban area.

The significant advantage of using the obtained calibrated coefficients is observed over the existing coefficients embedded in CFD tools as well as the ones recommended by other calibration methods in literature. Thus, this study proves the necessity of finding a group of customized optimum closure coefficients for RANS turbulence models suitable for a wide range of urban flow problems.
\end{abstract}

Keywords: Calibration, Urban airflow simulation, Stochastic optimization, Accuracy improvement, Computational fluid dynamics, Natural ventilation

\footnotetext{
${ }^{1}$ Corresponding author at: Wind and Fluid Engineering Research Center, Niigata Institute of Technology, Kashiwazaki, Japan.

Shirzadi@niit.ac.jp
} 


\section{Introduction}

Increasing applications of computational fluid dynamics (CFD) in the urban studies reflects on its importance in research and practical engineering applications (Blocken, 2014; Jiru and Bitsuamlak, 2010). Different aspects of airflow in urban environment, including pedestrian level wind comfort (Blocken et al., 2016; Fadl and Karadelis, 2013; Iqbal and Chan, 2016; Mirzaei and Haghighat, 2011; Serteser and Karadag, 2018; Tsang et al., 2012; Wang et al., 2019; Yoshie et al., 2007), building energy (Allegrini et al., 2015; Charisi et al., 2019; Cook et al., 2008; Fan and Ito, 2012; Malys et al., 2015; Mochida et al., 2006b; Zhai et al., 2002; Zhang et al., 2018), pollution dispersion (Abbassi et al., 2019; Gonzalez Olivardia et al., 2019; Haghighat and Mirzaei, 2011; Longo et al., 2019; Luo et al., 2016; Tominaga and Stathopoulos, 2011, 2010; Yoshie et al., 2011), and urban heat island (Allegrini et al., 2015; Hien et al., 2012; Kawamoto, 2016; Mirzaei et al., 2015; Priyadarsini, 2009) are the main subject areas tackled by CFD models.

CFD modeling based on large eddy simulation (LES) is one of the advanced approaches for such applications, in which the Navier-Stokes equations are resolved in time and space, and it is gaining a high popularity in research studies related to wind engineering and urban airflow simulation (Ikegaya et al., 2019). In the LES approach, small scale turbulent eddies are filtered and modeled using sub-grid turbulence models while large scale eddies are resolved. The higher accuracy of LES models in comparison with RANS models makes them more favorable for scientific research, but their significantly higher computational cost and data storage requirement place them as an impractical approach for many engineering problems. For example, the runtime of conducting a LES using a coarse mesh setting over an urban scale model of Michel-Stadt case was about 35 days by utilization of 100 CPU's (Tolias et al., 2018); this intensive computational cost was only used to resolve about 160 seconds of the transient flow field. For a simple case of an isolated high-rise building, conducting LES by (Liu and Niu, 2016) took 120 hours using a 6core PC. As another example, a total number of 32 nodes with $8 \times 2$ cores were utilized by (Okaze et al., 2017) in order to reproduce an accurate three dimensional (3D) LES model of the approaching inflow boundary condition over roughness blocks and spires of an atmospheric wind tunnel. In general, considering the fact that, for practical design stages, several calculation cases for multiple wind directions are required, the limitations of LES become even more evident (Yoshie et al., 2007).

Due to the above-mentioned limitations of LES, most of CFD models adapted to engineering applications are developed based on discretization of the Reynolds-averaged Navier-Stokes equations under either steady (SRANS) or unsteady (URANS) conditions. In general, RANS 
models have lower computational costs of about an order of magnitude in comparison with LES (Blocken, 2018), which makes them more suitable tools for design and analysis purposes. While the distribution of mean airflow can be obtained by RANS models, various turbulence model families are developed for them to replicate the airflow fluctuations as well. Most commonly adapted turbulence model families in urban airflow studies are two-equation turbulence models, including the standard $k-\varepsilon$ (Launder and Spalding, 1974), RNG $k-\varepsilon$ (Yakhot and Orszag, 1986), Realizable $k-\varepsilon$ (Shih et al., 1995), and $k-\omega$ SST (Menter, 1994). For these models well documented guidelines (Franke et al., 2007; Tominaga et al., 2008b) are available for urban airflow simulations, inherently being developed based on the comparison of RANS model results with wind tunnel experiments. Hence, with respect to CPU time and availability of these practical guidelines, RANS models are preferred for many applications such as building energy simulation, where mean flow quantities are required. However, it is worthy to note that, in some applications like those involving dispersion of toxic agent, estimation of mean-flow quantities are not sufficient and transient fluctuations of flow parameters are required (Dejoan et al., 2007).

One drawback of the RANS models is the low accuracy of two-equation turbulence models in prediction of mean-flow quantities in weak wind regions around and behind buildings (Mochida et al., 2002; Murakami et al., 1996; Shirasawa et al., 2006; Tominaga, 2015). In general, inaccuracy of two-equation turbulence models is resulted from the simplifications in the turbulent-viscosity hypothesis and derived equations for the dissipation rate $(\varepsilon)$ of the turbulent kinetic energy (TKE) (Pope, 2001). The turbulent viscosity hypothesis has been developed with the assumption of a direct relationship between the Reynolds-stress anisotropy and the mean velocity gradient adapted from an analogy to the molecular viscous stress in Newtonian fluids. Nevertheless, as discussed in (Pope, 2001), the physics of turbulence is completely different from the molecular process, which was utilized to reach the Newtonian viscous stress law. On the other hand, it is impossible to solve the exact transport equation of $\varepsilon$ as it requires further modeling and developing empirical equations (Wilcox, 1998).

Hence, the closure equations in RANS family models were mainly hypothesized as completely empirical equations, consisting of several unknown coefficients approximated with observation of few fundamental flows, including homogenous isotropic decaying turbulence, fully developed channel flow, and simple shear flow (Pope, 2001). Nonetheless, there is a marginal similarity between these fundamental flows and airflow around buildings in atmospheric boundary layer $(A B L)$. Therefore, this led to a series of research to calibrate the closure coefficients of the $k-\varepsilon$ model for ABL flow over a flat terrain (Duynkerke, 1988) and a complex terrain (Detering and 
Etling, 1985), flow around a high-rise buildings (Iqbal and Chan, 2016; Mittal et al., 2019a, 2019b; Shirzadi et al., 2017), and flow inside a street canyon (Glover et al., 2011; Guillas et al., 2014). The calibration of the closure coefficients of other turbulence models was also considered for prediction of the wind pressure over low-rise buildings using the Spalart-Allmaras and RNG $k-\varepsilon$ models (Gimenez and Bre, 2019) and for prediction of the pollution dispersion around building blocks using the $k-\omega S S T$ model (Yu and Thé, 2016).

Considering the low accuracy of RANS models in addition to their popularity and practicality in engineering problems, an improvement in the accuracy of RANS models can be a pivotal step to obtain more reliable numerical results with affordable computational resources while avoiding complexity and high computational cost of high-resolution CFD models such as LES. To this end, the authors proposed a systematic framework for improving the accuracy of RANS turbulence models for simulation of urban airflows studies in ABL flows, utilizing a stochastic optimization method combined with different statistical analysis and approximation models (Shirzadi et al., 2018a). In this paper, the applicability of the proposed framework is discussed for several case studies while the improved models are compared against some reference cases in the literature in the field of urban and building airflow studies. Furthermore, the limitations and future visions of the proposed framework is discussed. In section 2, a brief history of the closure coefficients calibration is presented. The proposed framework is introduced in section 3 and then the selected case studies are described in section 4 while the results are discussed in section 5 . In section 6 , the values of the calibrated closure coefficients are compared with the existing ones in literature. Eventually, the possibility to obtain a general trend to calibrate closure coefficients for airflows in urban areas is discussed.

\section{A brief history of the closure coefficients calibration for $A B L$ flows}

In this section, a brief review is presented about the values of the closure coefficient used in different studies of $A B L$ flows. As explained before, the Reynolds stresses can be related to the mean velocity gradients and eddy viscosity (turbulent viscosity) by the gradient diffusion hypothesis as follows (Launder and Spalding, 1974):

$$
-\rho \overline{u_{\imath} u_{J}}=\mu_{t}\left(\frac{\partial U_{i}}{\partial x_{j}}+\frac{\partial U_{j}}{\partial x_{i}}\right)-\frac{2}{3} \delta_{i j} \rho k
$$

where $U_{i}$ is the component of the mean velocity in streamwise, lateral, and vertical directions, $\rho$ is the air density, and $\mu_{t}$ is the eddy viscosity (turbulent viscosity), which can be defined as below:

$$
\mu_{t}=C_{\mu} \rho \frac{k^{2}}{\varepsilon}
$$


In the standard $k-\varepsilon$ model, values of the turbulent kinetic energy $(k)$ and its dissipation rate $(\varepsilon)$ come directly from their differential transport equations:

$$
\begin{aligned}
& \frac{\partial \rho U_{j} k}{\partial x_{j}}=\frac{\partial}{x_{j}}\left[\left(\mu+\frac{\mu_{t}}{\sigma_{k}}\right) \frac{\partial k}{x_{j}}\right]+P_{k}-\rho \varepsilon+P_{k b} \\
& \frac{\partial \rho U_{j} \varepsilon}{\partial x_{j}}=\frac{\partial}{x_{j}}\left[\left(\mu+\frac{\mu_{t}}{\sigma_{\varepsilon}}\right) \frac{\partial \varepsilon}{x_{j}}\right]+\frac{\varepsilon}{k}\left(C_{\varepsilon 1} P_{k}-C_{\varepsilon 2} \rho \varepsilon+C_{\varepsilon 1} P_{\varepsilon b}\right)
\end{aligned}
$$

where $\mu$ is the molecular viscosity and $P_{k}$ is the production of turbulence due to shear:

$$
P_{k}=\mu_{t} S^{2}
$$

where $\mathrm{S}=\sqrt{2 S_{i j} S_{i j}}$ is the magnitude of the mean strain rate. $P_{k b}$ and $P_{\varepsilon b}$ are the buoyancy turbulence production and dissipation terms, respectively:

$$
\begin{aligned}
P_{k b} & =\frac{\mu_{t}}{\sigma_{p}} \beta g_{i} \frac{\partial T}{\partial x_{i}} \\
P_{\varepsilon b} & =\max \left(0, P_{k b}\right)
\end{aligned}
$$

where $T$ and $g_{i}$ are respectively the air temperature and gravity vector while $\sigma_{p}=0.9$ is the turbulent Prandtl Number and $\beta$ is the thermal expansion coefficient.

A disadvantage of the $P_{k}$ definition in equation (5) is overprediction of TKE around the stagnation point where the shear strain rate is very high (Murakami et al., 1990). Hence, a modification on the standard $k-\varepsilon$ model, named LK modification, was proposed by (Kato and Launder, 1993) in which the magnitude of vorticity rate $\left(\Omega=\sqrt{2 \Omega_{i j} \Omega_{i j}}\right)$ is used in $P_{k}$ definition:

$$
P_{k}=\mu_{t} S \Omega
$$

The vorticity tensor $\Omega_{i j}$ is calculated as below:

$$
\Omega_{i j}=\frac{1}{2}\left(\frac{\partial U_{i}}{\partial x_{j}}-\frac{\partial U_{j}}{\partial x_{i}}\right)
$$

The transport equation for $k$ is directly derived by multiplying the fluctuating components to the Navier-Stokes equations and time-averaging the products. It is possible to drive an exact equation for $\varepsilon$ using the same procedure and to define $\varepsilon$ as $\varepsilon=\frac{\mu}{\rho} \frac{\overline{\partial u_{l}^{\prime}}}{\partial x_{k}} \frac{\partial u_{l}^{\prime}}{\partial x_{k}}\left(u_{i}^{\prime}\right.$ is the $i$ th component of the instantaneous velocity vector), but the resulting equation becomes far more complicated than the $k$ equation and involves many unknowns high-order correlations for fluctuating velocity, pressure and velocity gradients, which are not possible to measure experimentally (Wilcox, 1998). Hence, the equation for $\varepsilon$ is derived as an entirely empirical equation, which has unknown constants named as closure coefficients that should be determined to close the system of equations. The values of the closure coefficients appeared in the above equations are found as $C_{\varepsilon 1}=1.44, C_{\varepsilon 2}=1.92, C_{\mu}=0.09, \sigma_{\varepsilon}=1.3, \sigma_{k}=1$ based on (Launder and Spalding, 1974). 
These values are used as default values in many commercial CFD software such as ANSYS CFX, ANSYS Fluent, PHOENIX, STAR CCM+ in addition to open-source CFD codes such as OpenFOAM.

These coefficients are obtained based on different experimental measurements and numerical analyses using direct numerical simulation (DNS) of fundamental flows. As stated in (Pope, 2001; Wilcox, 1998), the values of the closure coefficients were selected based on a compromise to achieve an acceptable accuracy and applicability for a wide range of flow problems, and not only for airflows in urban and building studies. However, more accurate analysis of the standard $k-\varepsilon$ model's closure coefficients, as well as experimental and DNS results of fundamental flows, i.e. homogenous isotropic decaying turbulence, log-law region of fully developed channel flow, fully developed turbulence channel flow, and simple shear flows, reveals noticeable deviations and uncertainties in these values. For instance, results of a fully developed channel flow by (Kim et al., 1987) show the value of $C_{\mu}$ to be in a range between 0.06 to 0.095 , while for a temporal mixing layer, a wider range of 0.07 to 0.11 was found using a DNS model by (Rogers and Moser, 1994). The proposed value of $C_{\mu}$ in the standard $k-\varepsilon$ model is 0.09 , which is very close to the average of these two ranges just for regions far from the solid walls. Another example of such variability in the values of the closure coefficients can be found by looking at the homogeneous shear flow, which was experimentally studies by (Tavoularis and Karnik, 1989). The experimental results showed that the value of $\frac{C_{\varepsilon 2}-1}{C_{\varepsilon 1}-1}$ is in a range between 1.33 and 1.75 while this ratio becomes about 2.09 for the default values of the standard $k-\varepsilon$ model. As another example, the value of the decay exponent $\left(n=\frac{1}{C_{\varepsilon 2}-1}\right)$ of the homogenous isotropic decaying turbulence flow, which was measured experimentally, is in a range from 1.15 to 1.45. However, for the standard $k-\varepsilon$ model, $n=1.08$, which is clearly outside of the experimental range (Pope, 2001). Regarding the simulation of urban airflows, some researchers proposed different values for the closure coefficients rather than using the default values in the standard $k-\varepsilon$ model. For instance, (Duynkerke, 1988) showed that more accurate results using the standard $k-\varepsilon$ model can be obtained for neutral and stable ABLs over flat terrains if the default values are replaced with $C_{\mu}=0.033, C_{\varepsilon 1}=1.46, C_{\varepsilon 2}=1.85$, and $\sigma_{\varepsilon}=2.38$. For a neutral $\mathrm{ABL}$ over complex terrains, (Detering and Etling, 1985) proposed different closure coefficients of $C_{\varepsilon 1}=1.13$, $C_{\varepsilon 2}=1.9, \sigma_{\varepsilon}=1.29, \sigma_{k}=0.74$. In the study conducted by (Glover et al., 2011), a Bayesian calibration of the closure coefficients was conducted for a street canyon flow to find these values as $C_{\varepsilon 1}=1, C_{\varepsilon 2}=2.2, C_{\mu}=0.12, \sigma_{\varepsilon}=0.42, \sigma_{k}=0.462$. In a similar study by (Guillas et al., 2014), the same values were reported for an idealized street canyon while (Iqbal and Chan, 2016) 
obtained very close values for pedestrian wind environment around a group of high-rise crossshaped buildings using a simple parametric study.

\section{Framework for RANS turbulence model calibration}

A schematic of the proposed framework for RANS CFD model calibration is shown in Figure 1. The framework consists of two main steps. Step 1 deals with the case study definition and acquiring high-quality data from different sources to be utilized for the calibration process. Step 2 is the calibration process in which the high-quality data obtained from step 1 are utilized to calibrate the RANS turbulence model.

\subsection{Step 1: high-quality data acquisition and validation metrics}

This step includes four sub-steps: 1-1) Case study definition, 1-2) Determination of focused output parameters, 1-3) High-quality data acquisition, 1-4) Validation metrics calculation for focused output parameters. Through these sub-steps, required data for the closure coefficients calibration are organized systematically by conducting a series of CFD simulations, acquiring high-quality data from different resources, and performing statistical analyses.

In sub-step 1-1, after preparation of the CFD model, e.g., geometry generation, boundary condition implementation, and applying CFD solver settings in accordance with the guidelines by (Franke et al., 2007; Tominaga et al., 2008b), a suitable zero equation, one-equation, or twoequation turbulence model will be selected although two-equation models are more popular in urban flow simulations. Practical information about the performance of two-equations turbulence models can be found in parametric studies conducted by AIJ group (Mochida et al., 2006a, 2002; Tominaga et al., 2008a; Yoshie et al., 2007). The $k-\varepsilon$ family models, including the standard $k-$ $\varepsilon$ (Launder and Spalding, 1974), RNG $k-\varepsilon$ (Yakhot et al., 1992), and Realizable $k-\varepsilon$ (Shih et al., 1995), was proved to be an acceptable option for many practical engineering problems. Furthermore, these models have less number of closure coefficients in comparison with the $k-$ $\omega$ SST (Menter, 1994) model, which makes them a better candidate for the closure coefficient calibration.

In sub-step 1-2, after selection of the turbulence model, the focused output parameters of the CFD model should be chosen for the calibration purpose. For instance, for pedestrian comfort studies, the focused parameters are wind velocity distribution and/or pollution concentration at the pedestrian level, or for building energy evaluations, the focused parameters are wind surface pressures over building walls and/or crossing airflow rate.

In sub-step 1-3, high-quality data should be provided to define suitable validation metrics required for the turbulence model calibration obtained from Step 2. At this stage, different sources can be used depending on the focused output parameters and the aimed level of accuracy. As it 
can be seen in Figure 1, various options can be considered for obtaining high-quality data, including in-situ or field measurement, wind-tunnel measurement, and high-fidelity CFD models. As a general consideration for selection of the measurement and sampling points, locations where the RANS models are known to be inaccurate, such as wake regions behind buildings, separated flow areas over side walls and roof, and airflow around openings, are generally favorable. As another consideration, when a high-fidelity CFD model is selected for the calibration, the similarity between the RANS and high-fidelity models is very important. It can be defined in terms of morphological parameters such as urban planar and frontal area ratios, and flow conditions such as Reynolds number.

After obtaining required high-quality data, in sub-step 1-4, validation metrics should be employed to quantitatively investigate the level of agreement between the CFD and high-quality datasets. The most common validation metrics for environmental and urban flow studies are those proposed by (Schatzmann, 2010), including the hit rate $q$, fraction of the predictions within a factor of 2 of the observations (FAC2), fractional bias $(F B)$, and normalized mean square error $(N M S E)$ :

$$
\begin{aligned}
& q=\frac{1}{N} \sum_{i=1}^{N} n_{i} \quad \text { if }\left|\frac{P_{i}-Q_{i}}{Q_{i}}\right| \leq D_{q} \text { or }\left|P_{i}-Q_{i}\right| \leq W_{q} \quad n_{i}=1 \text { else } n_{i}=0 \\
& F B=\frac{[Q]-[P]}{0.5([Q]+[P])} \\
& N M S E=\frac{\left[\left(Q_{i}-P_{i}\right)^{2}\right]}{[Q][P]} \\
& F A C 2=\frac{1}{N} \sum_{i=1}^{N} n_{i} \quad n_{i}=1 \quad \text { if } 0.5 \leq \frac{P_{i}}{Q_{i}} \leq 2 \text { else } n_{i}=0
\end{aligned}
$$

where $O_{i}$ and $P_{i}$ are the measured and computed values of a given variable for sample $i$, respectively. $N$ is the number of data points used in the calibration process. The ideal value of the validation metrics for a complete agreement between two data series is 1 for $q$ and $F A C 2$, and 0 for $F B$ and NMSE. 


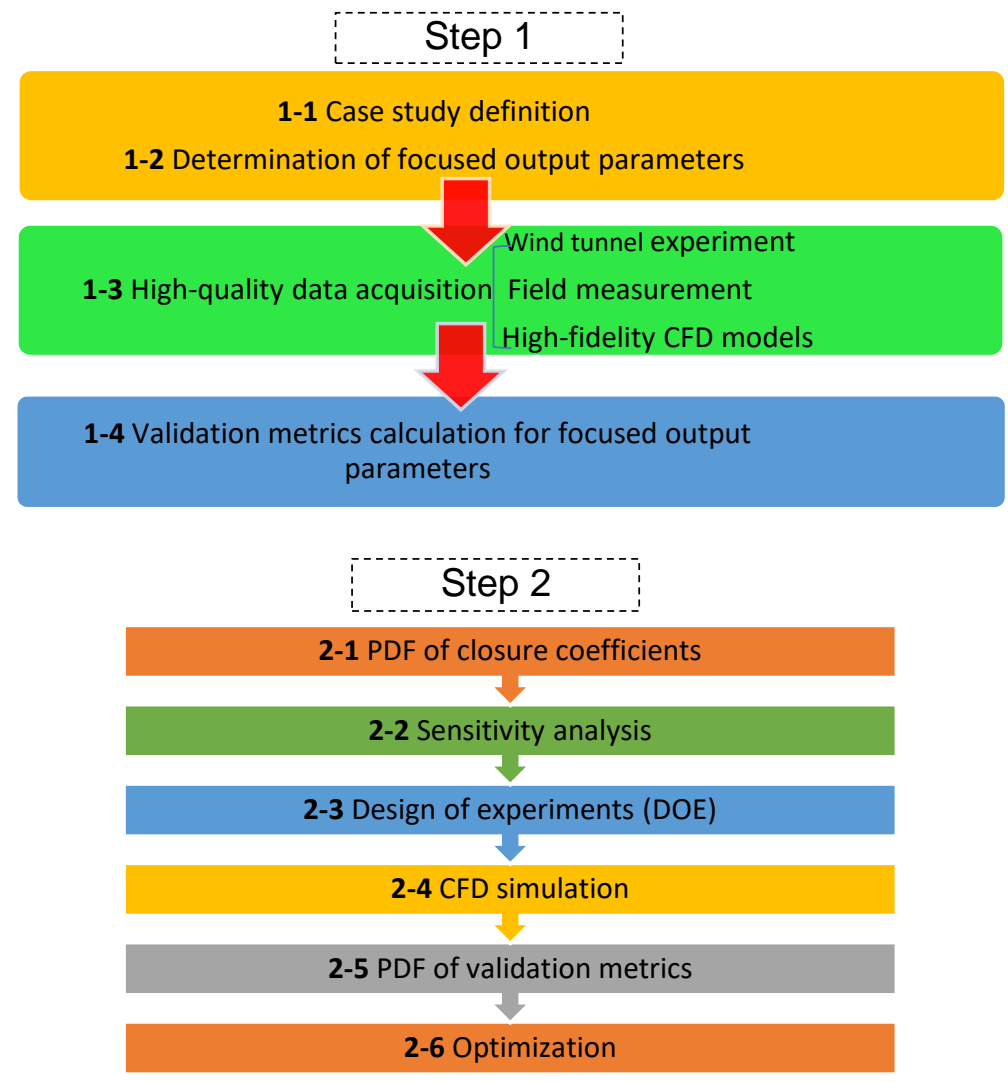

Figure 1 Framework of RANS CFD models calibration

\subsection{Step-2: calibration of closure coefficients}

The second step of the proposed framework includes six sub-steps: 2-1) Calculation of probability density function (PDF) of closure coefficients, 2-2) Sensitivity study, 2-3) Design of the experiment (DOE), 2-4) CFD simulations, 2-5) Calculation of PDF of validation metrics, 2-6) Optimization campaign. In this step, closure coefficients of the selected turbulence model are considered as variables in an optimization process to find the best agreement between the CFD and the acquired high-quality datasets. Hence, the optimization variables are the closure coefficients while the objective function is defined based on a combination of the selected validation metrics.

In sub-step 2-1, PDFs of all the closure coefficients are obtained according to available information about the history of model development and experimental data in literature. As a general consideration, uniform PDF is a suitable choice as there is not enough statistical information about the closure coefficients of RANS turbulence models.

After calculating the PDF of the closure coefficients, in sub-step 2-2, a sensitivity analysis is required to identify the most effective closure coefficients on the CFD accuracy. Sensitivity analysis can be conducted using a simple model such as one-factor-at-a-time method (OFAT) or 
a complex one such as Latin Hypercube sampling (Montgomery et al., 2009). If the CFD accuracy is insensitive to a certain closure coefficient, it can be removed from the calibration parameters to minimize the associated computational cost and complexity of the optimization process.

In sub-step 2-3, a suitable design of experiment (DOE) method, e.g. Monte Carlo Sampling (MS), is utilized to generate a database for CFD samples according to the PDF of the closure coefficients. Then, the CFD samples are solved in sub-step 2-4, and in sub-step 2-5, CFD results are post-processed to obtain the PDF of the selected validation metrics as well as their mean value and standard deviation.

Finally, in sub-step 2-6, an optimization solver is used to find the best set of the closure coefficients according the calculated validation metrics of the CFD database. An appropriate objective function is defined to minimize the deviation of the validation metrics and their ideal values. For more reliable calibration, stochastic optimization (reliability-based) algorithms can be used in which the objective function involves two terms to minimize (1) the deviation between the mean value of the validation metrics and ideal values, and (2) the standard deviation of the validation metrics. The second term enhances the reliability of the calibration process via reducing the uncertainty of the validation metrics caused by the uncertainty of the closure coefficients. More details about the stochastic optimization are provided in the next section.

If enough CFD samples are generated during the database generation step, approximation models (Beta models) based on an artificial neural network (ANN) or response surface model (RSM) can be created and coupled to the optimization solver. Otherwise, the CFD solver should be coupled directly to the optimization solver. After reaching a suitable level of convergence for the optimization process, the optimal values of the closure coefficients can be found.

Number of CFD simulations required for a successful calibration process depends on the complexity of the reference CFD model, the number of the measurement points used during the optimization process, and the convergence level of the CFD and optimization solvers. One option to reduce the computational cost is to utilize a coarse mesh setting for the CFD model in the database generation and optimization (sub-steps 2-3 to 2-5 in Figure 1). The effectiveness of the calibration process using a coarse mesh may be checked during the optimization process by applying the calibrated coefficients into the reference case using a finer mesh setting.

\section{Case studies description}

In this section, performance of the proposed calibration framework is investigated using three different case studies. A schematic of each case is presented in Figure 2. Case 1 is an isolated high-rise building placed in an unstable ABL (Shirzadi et al., 2017). Case 2 is a sheltered building model subjected to a cross-ventilation flow through two openings on its windward and leeward 
façades; All surrounding buildings are arranged in a regular configuration with a planar area ratio of 0.25 and are assumed to have no cross-ventilation (Shirzadi et al., 2018a). Case 3 consists of a group of 31 low-rise buildings with the same dimensions in a regular arrangement with a planar area ratio of 0.4 , which represents a highly-dense urban area (Shirzadi et al., 2018b). All buildings in Case 3 are considered to be sealed.

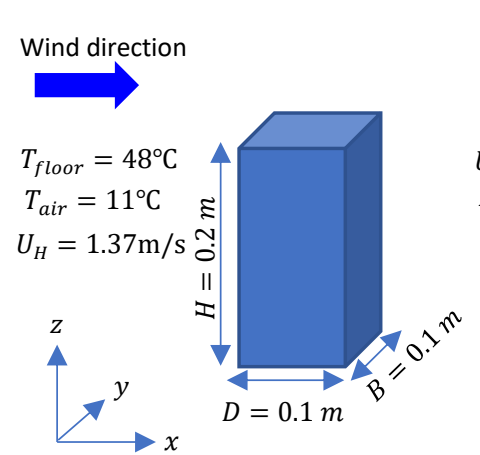

(a) Case 1

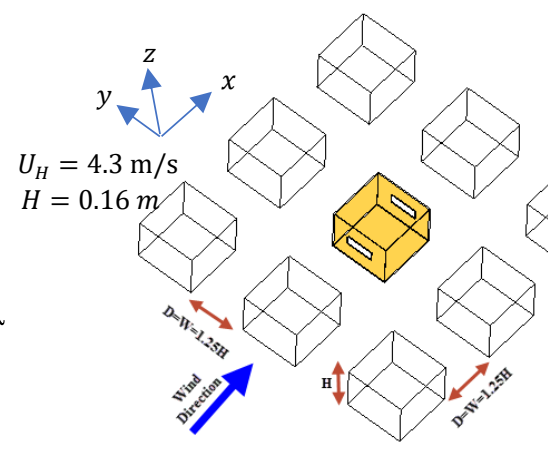

(b) Case 2

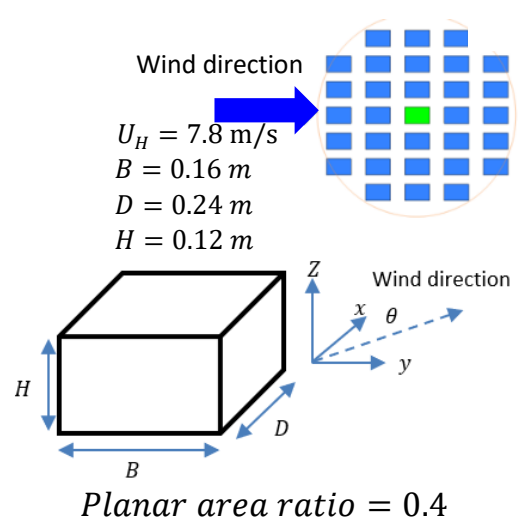

(c) Case 3

Figure 2 Schematic of case studies: (a) case 1- an isolated high-rise building, (b) case 2 - a sheltered cross-ventilated building, and (c) case 3 - a sheltered low-rise building in a highlydense configuration

CFD and calibration parameters for these cases are shown in Table 1. For all cases, the standard $k-\varepsilon$ model with LK modification (eq. (8)) was used. It has been reported that the LK modification can improve the prediction accuracy of urban airflows (Kurabuchi et al., 2000; Shao et al., 2012; Tominaga et al., 2008a; Tsuchiya et al., 1997). For Case 1 and Case 2, a stochastic optimization method was utilized. For the selected validation metrics, the mean value $\left(\mu_{y_{i}}\right)$ and the standard deviation $\left(\sigma_{y_{i}}\right)$ was calculated for each set of the closure coefficients. Then, they were used to define the objective function, which is a weighted-sum average of $\mu_{y_{i}}$ and $\sigma_{y_{i}}$, as follows (Koch et al., 2004):

$$
F=\sum_{i=1}^{l}\left[\frac{w_{1_{i}}}{s_{1_{i}}}\left(\mu_{y_{i}}-M_{i}\right)^{2}+\frac{w_{2_{i}}}{s_{2_{i}}} \sigma_{y_{i}}^{2}\right]
$$

where $w_{1_{i}}$ and $w_{2_{i}}$ are the weighting factors. $s_{1_{i}}$ and $s_{2_{i}}$ are the scale factors related to each term. $M_{i}$ is the ideal value of $i$ th validation metric and $l$ is the total number of sampling points used in the optimization process. The optimization solver is based on the Nonlinear Programing with NonMonotone and Distributed Line Search (NLPQLP) method (Schittkowski, 2006). Other optimization methods such as those based on the genetic algorithm (GA) can be used, but in 
general they require more CFD samples to reach an optimal solution. For Case 3, no optimization was conducted, and optimal values of the closure coefficients were directly selected based on a sensitivity analysis.

Table 1 Details of CFD and optimization settings for RANS calibration case studies

\begin{tabular}{|c|c|c|c|c|c|c|c|}
\hline & $\begin{array}{c}\text { Baseline } \\
\text { Turbulence } \\
\text { model }\end{array}$ & $\begin{array}{c}\text { Focused output } \\
\text { parameters }\end{array}$ & $\begin{array}{l}\text { Measurement } \\
\text { points No. for } \\
\text { calibration }\end{array}$ & $\begin{array}{l}\text { High quality } \\
\text { data source }\end{array}$ & $\begin{array}{c}\text { Design of } \\
\text { experiment } \\
\text { (DOE) }\end{array}$ & $\begin{array}{l}\text { Number } \\
\text { of CFD } \\
\text { samples }\end{array}$ & $\begin{array}{c}\text { Optimization } \\
\text { solver }\end{array}$ \\
\hline Case-1 & $\begin{array}{c}\text { Standard } k-\varepsilon \\
\text { with LK } \\
\text { modification }\end{array}$ & $\begin{array}{c}U, k, T \text { at the wake region } \\
\text { behind the building (wind } \\
\text { angle } \theta=0^{\circ} \text { ) }\end{array}$ & 48 & $\begin{array}{c}\text { Wind tunnel } \\
\text { experiment } \\
\text { (Yoshie et al., } \\
\text { 2011) } \\
\end{array}$ & $\begin{array}{l}\text { Monte Carlo } \\
\text { Sampling }\end{array}$ & 450 & $\begin{array}{c}\text { NLPQLP } \\
\text { (Schittkowski, } \\
\text { 2006) }\end{array}$ \\
\hline Case-2 & $\begin{array}{c}\text { Standard } k-\varepsilon \\
\text { with LK } \\
\text { modification }\end{array}$ & $\begin{array}{l}U \text { and } K \text { inside the building, } \\
\text { and crossing airflow rate } \\
\text { through the openings (wind } \\
\text { angle } \theta=0^{\circ} \text { ) }\end{array}$ & 63 & $\begin{array}{l}\text { Wind tunnel } \\
\text { experiment } \\
\text { (Tominaga } \\
\text { and Blocken, } \\
\text { 2015) }\end{array}$ & $\begin{array}{l}\text { Monte Carlo } \\
\text { Sampling }\end{array}$ & 250 & $\begin{array}{c}\text { NLPQLP } \\
\text { (Schittkowski, } \\
\text { 2006) }\end{array}$ \\
\hline Case-3 & $\begin{array}{c}\text { Standard } \\
k-\varepsilon \text { with } \\
\text { LK } \\
\text { modification } \\
\end{array}$ & $\begin{array}{l}\text { Wind surface pressure over } \\
\text { building façades (wind angle } \\
\qquad 0^{\circ} \leq \theta \leq 90^{\circ} \text { ) }\end{array}$ & 256 & $\begin{array}{c}\text { Wind tunnel } \\
\text { experiment } \\
\text { (Quan et al., } \\
\text { 2007) } \\
\end{array}$ & $\begin{array}{c}\text { OFAT } \\
\text { (Campolongo } \\
\text { et al., 2007) }\end{array}$ & 40 & $\begin{array}{l}\text { Optimal values } \\
\text { are obtained } \\
\text { directly from } \\
\text { DOE results }\end{array}$ \\
\hline
\end{tabular}

\section{Results}

In this section, results of the calibrated models of three case studies are presented and compared with the CFD models using default closure coefficients.

\subsection{Case 1}

In Figure 3, the distribution of TKE around the high-rise building is compared against the experimental measurements over a central vertical plane $(y / H=0)$ and a horizontal plane near the ground $\left(\frac{z}{H}=0.025\right)$. The results of the CFD model with the default closure coefficients over the vertical and horizontal planes exhibit two well-known deficiency of two-equation turbulence models, i.e., a high level of TKE around the windward wall and above the roof, and a significant underprediction of TKE and momentum diffusion inside the wake region behind the building (Tominaga, 2015). The calibrated model shows significant improvement in prediction of TKE level in comparison with the reference model. The TKE level in front of the windward wall is lower than the reference model while it is noticeably higher in the wake region behind the building. The observed difference in the TKE prediction in the wake region by the calibrated model and the experimental results refers to the fact that the steady RANS models are inherently incapable of calculating the contribution of TKE due to the large-scale fluctuations behind the building (see (Tominaga, 2015)). 


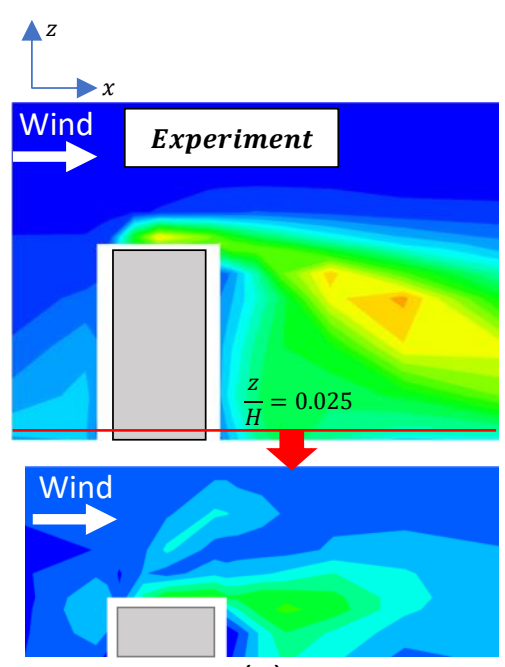

(a)

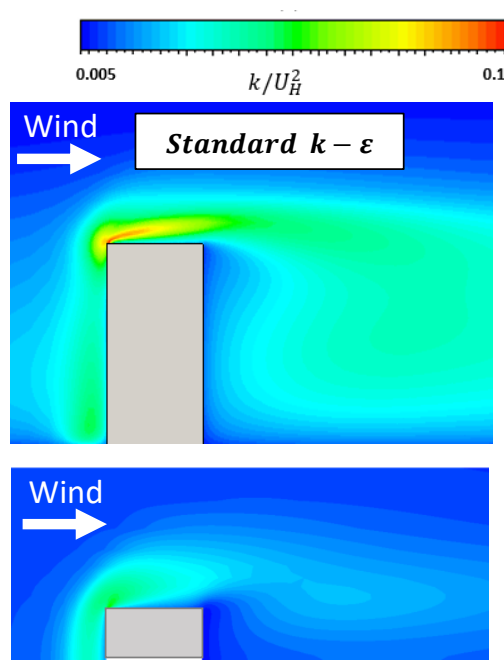

(b)
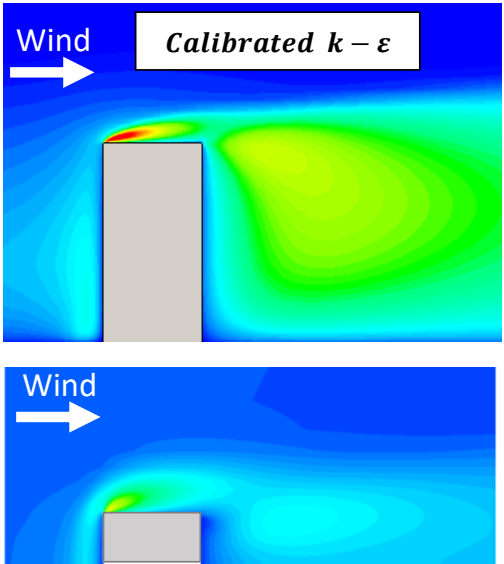

(c)

Figure 3 Distribution of TKE around the high-rise building (Case 1) for (a) wind tunnel experiment (Yoshie et al., 2011), (b) default closure coefficients, and (c) calibrated closure coefficients

The vertical distribution of the streamwise velocity $\frac{U}{U_{H}}$ over the vertical central plane is plotted in Figure 4(a). Both CFD models predict similar velocity profile over the vertical lines in front of the building $\left(\frac{x}{H}=-0.625\right)$ and above the roof $\left(\frac{x}{H}=-0.25\right)$. For the reference case with the default closure coefficients, the reverse flow in the wake region is overestimated due to the poor momentum mixing behind the building while a significant improvement in the prediction accuracy of the velocity distribution can be clearly observed for the calibrated model.

The contours of $\frac{U}{U_{H}}$ over the horizontal plane at $\frac{Z}{H}=0.025$ along with the streamlines are presented in Figure 4(a),(b),(c). A very long recirculation region behind the building is predicted by the $k-\varepsilon$ model with the default coefficients, which is noticeably longer than the one predicted by the experimental measurements. In contrast, in the calibrated model, the length of the recirculating region is considerably shorter and shows a good agreement with the experimental data.

Different sidewall reattachments are predicted by these two models. Whilst in the reference model, the separated flow does not reattach over the sidewall, the calibrated model shows a clear flow reattachment. A noticeable prediction improvement is obtained by the calibrated model in calculation of the reattachment length over the floor $\left(X_{f}\right)$. For the default closure coefficients, 
$X_{f}=0.26 \mathrm{~m}$, which is much longer than that of the experiment with the value of $X_{f}=0.096 \mathrm{~m}$, a value of $X_{f}=0.123 \mathrm{~m}$ is calculated by the calibrated model, which is closer to the experiment.

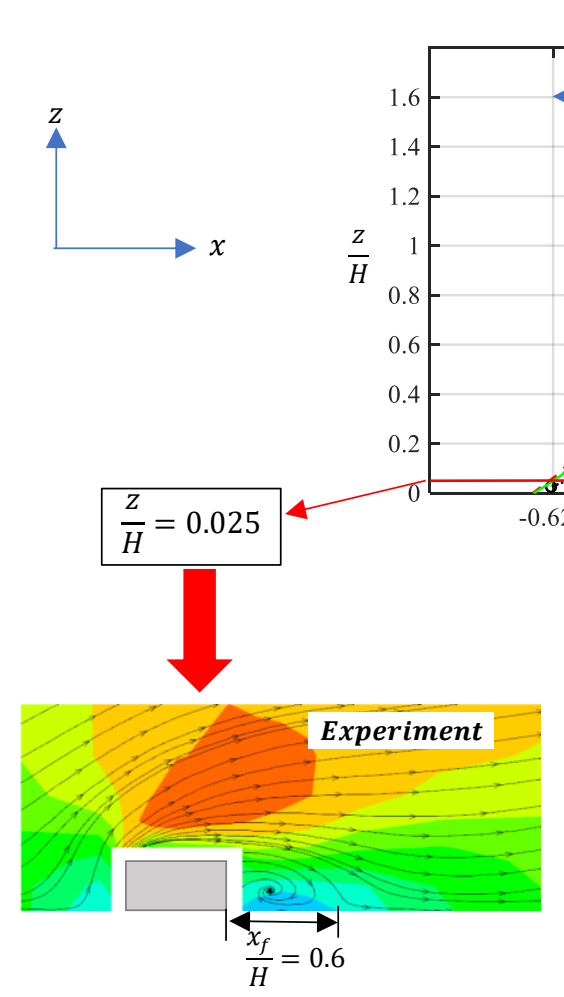

(b)

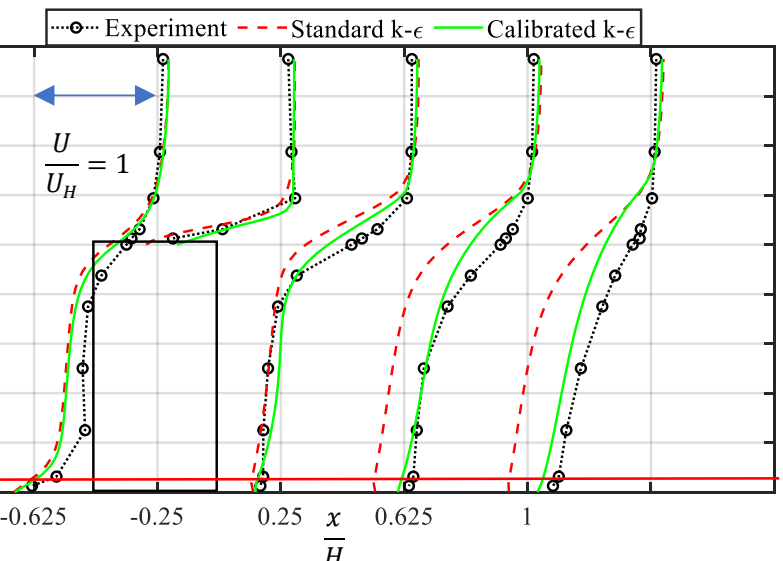

(a)

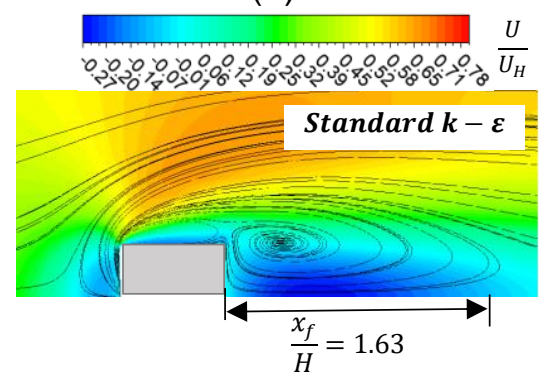

(c)

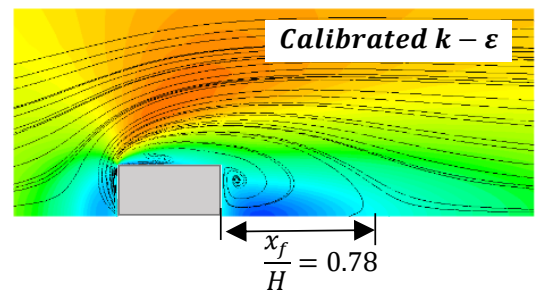

(d)

Figure 4 (a) Vertical profiles of the streamwise velocity around the building. Horizontal distribution of streamwise velocity and streamlines near the ground $\left(\frac{Z}{H}=0.025\right)$ obtained by (b) experiment (Yoshie et al., 2011), (c) default closure coefficients, and (d) calibrated closure

\subsection{Case 2}

\section{coefficients}

The time-averaged streamlines over a vertical central plane inside the sheltered crossventilated building are plotted in Figure 5 for both the standard and calibrated $k-\varepsilon$ models as well as the wind tunnel experimental results. The experimental result shows that a large counterclockwise recirculation forms inside the building while its center is near the leeward opening. For the standard $k-\varepsilon$ model with the default closure coefficients, a very large counterclockwise recirculating flow is predicted although its center is miscalculated far from the leeward opening and is located close to the center of the building. However, the results of the calibrated $k-\varepsilon$ shows a closer agreement with the experimental result.

The discrepancies between the standard $k-\varepsilon$ model and experimental result are mainly originated from the low accuracy of this model in the prediction of the roof separation/reattachment and the wake formed behind the upstream building, and also is due to their inherent poor accuracy in prediction of the TKE distribution inside the street canyon and 
target building as shown in Figure 5(b). In fact, low accuracy of the standard $k-\varepsilon$ model with the default closure coefficients in prediction of the momentum diffusion in the wake region between the upstream and downstream adjacent buildings and TKE distribution around the incoming jet result in an inaccurate calculation of the cross-ventilation through the target building. Surprisingly, the predicted direction of the airflow through the target building by the standard $k-\varepsilon$ model is completely inaccurate where it enters the building through the leeward opening and not through the windward one as observed in the experiment and calculated by the calibrated model (see Figure 5(a) and (c)).

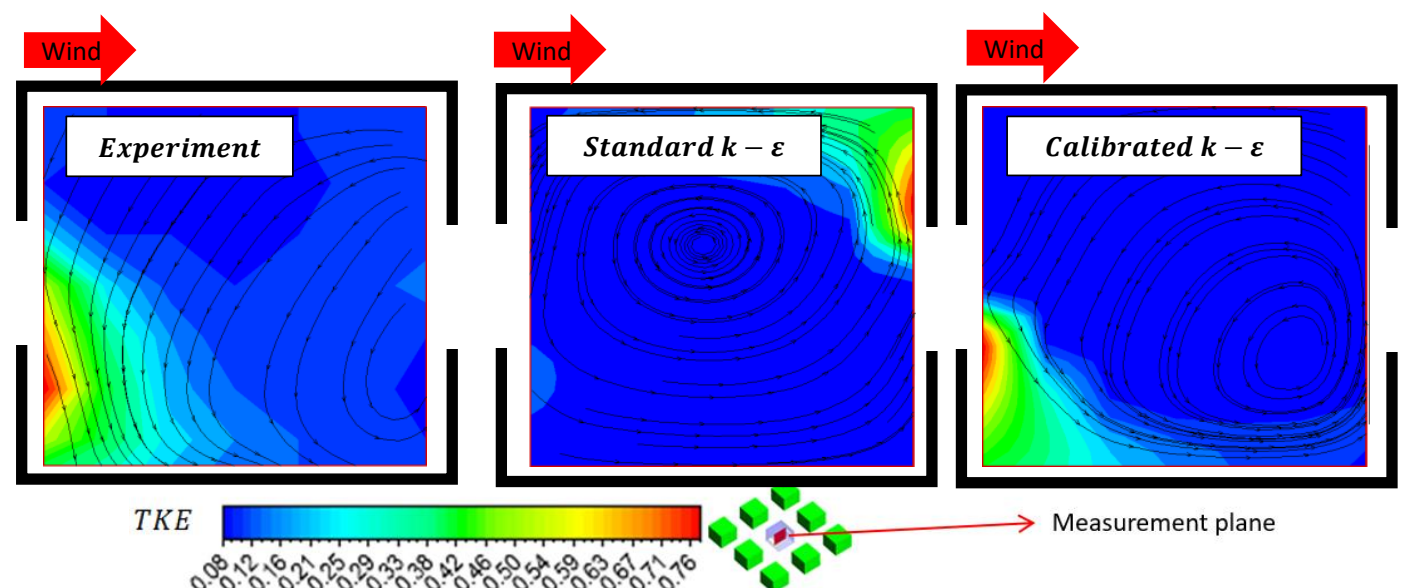

(a)

(b)

(c)

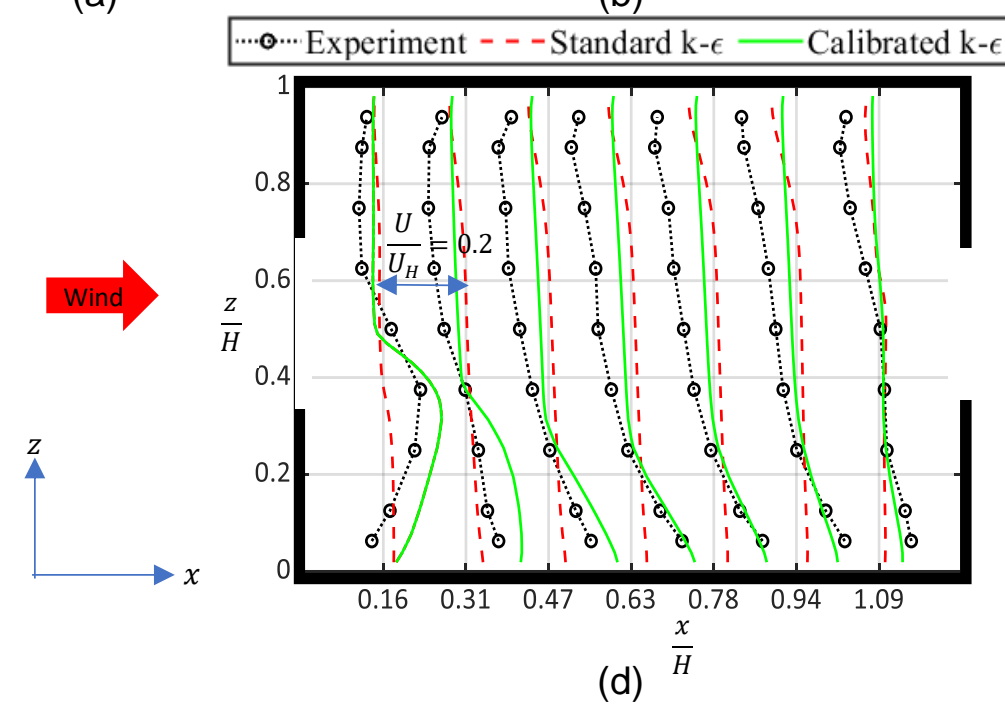

Figure 5 Distribution of TKE and streamlines over the central vertical plane obtained by (a) experiment, (b) standard $k-\varepsilon$, and (c) calibrated $k-\varepsilon$. (d) Distribution of the streamwise velocity over a vertical central plane inside the building

The vertical profiles of the streamwise velocity over a central vertical plane inside the building model is shown in Figure 5(d). As it can be seen from the experimental results, a clear windward jet is formed at $\frac{x}{H}=0.16$ and at $\frac{Z}{H}=0.4$ with a velocity of $\frac{U}{U_{H}}=0.1$. In contrast, for the standard 
$k-\varepsilon$ model, the streamwise velocity is almost zero over the vertical line at $\frac{x}{H}=0.16$ and the model fails to reproduce the windward jet, which is the main feature of the cross-ventilation. The calibrated model successfully predicts the windward jet with a velocity of $\frac{U}{U_{H}}=0.12$ at $\frac{x}{H}=0.16$ and $\frac{Z}{H}=0.4$, which is close to the experimental result. Furthermore, the vertical profiles of the streamwise velocity over the vertical plane far from the windward opening and near the ground show a better agreement between experiments and the calibrated model. Nevertheless, the streamwise velocity at the upper part of the target building is underestimated by the both models. It should be noted that the relative deviation between the airflow rate prediction by the standard $k-\varepsilon$ model and the experiment is about $100 \%$, while it noticeable decreases to $8 \%$ using the calibrated model.

\subsection{Case 3}

As stated in Table 1, for Case 3, the values of the surface wind pressure are utilized for the closure coefficient calibration rather than the flow field data, hence, only results for the surface wind pressure are shown here. In Figure 6, the surface-averaged wind pressure coefficient difference over the windward and leeward façades $\left(\Delta C_{P}=C_{P}^{\text {windward }}-C_{P}^{\text {leeward }}\right)$ is shown for the standard $k-\varepsilon$ model with the default and calibrated closure coefficients. The experimentally measured value of $\Delta C_{P}$ against the wind angles of $0^{\circ}, 22.5^{\circ}, 45^{\circ}$, and $67.5^{\circ}$ is $0.19,0.30,0.28$, and 0.16 , respectively. The results of the standard $k-\varepsilon$ model show a noticeable underprediction against all the wind angles with $\Delta C_{P}$ equals to $0.04,0.09,0.1,0.07$ against the wind angles of $0^{\circ}$, $22.5^{\circ}, 45^{\circ}$, and $67.5^{\circ}$. Significant improvement is obtained by the calibrated $k-\varepsilon$ model with $\Delta C_{P}$ values being $0.15,0.19,0.18$, and 0.11 against the wind angles of $0^{\circ}, 22.5^{\circ}, 45^{\circ}$, and $67.5^{\circ}$. Despite observed improvement by the calibrated model, the surface-averaged wind pressure coefficient differences are still lower than the experimental values against all wind angles. 


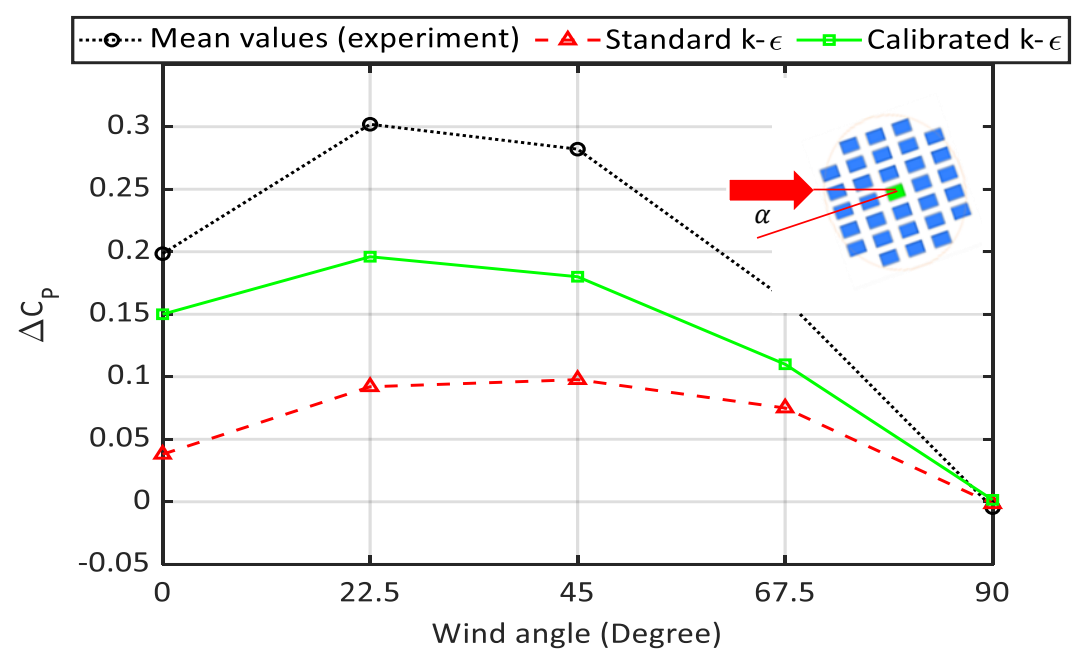

Figure 6 Surface-averaged wind pressure coefficient difference $\left(\Delta \boldsymbol{C}_{\boldsymbol{P}}\right)$ over the windward and leeward façades against different wind angles for Case 3

In Figure 7, the profiles of the surface wind pressure coefficient $\left(C_{P}\right)$ along a central line over windward and leeward façades and roof of the target building are plotted against the $0^{\circ}$ wind angle. Over the windward and leeward façades, between $0 \leq \frac{z}{H} \leq 0.5$, both CFD models underestimate $C_{P}$ while the calibrated $k-\varepsilon$ model calculates more accurate results between $0.5 \leq \frac{Z}{H} \leq 1$. In these regions, the standard $k-\varepsilon$ model's predictions are far from the experimental results. The superiority of the calibrated $k-\varepsilon$ model is more clearly demonstrated by looking at the $C_{P}$ variation over the roof, where the pressure recovery along the roof is very well predicted by the calibrated model and a close agreement is obtained with the experimental results. In contrast, a uniform pressure distribution is calculated by the standard $k-\varepsilon$ model, which is significantly higher than the experimental result.
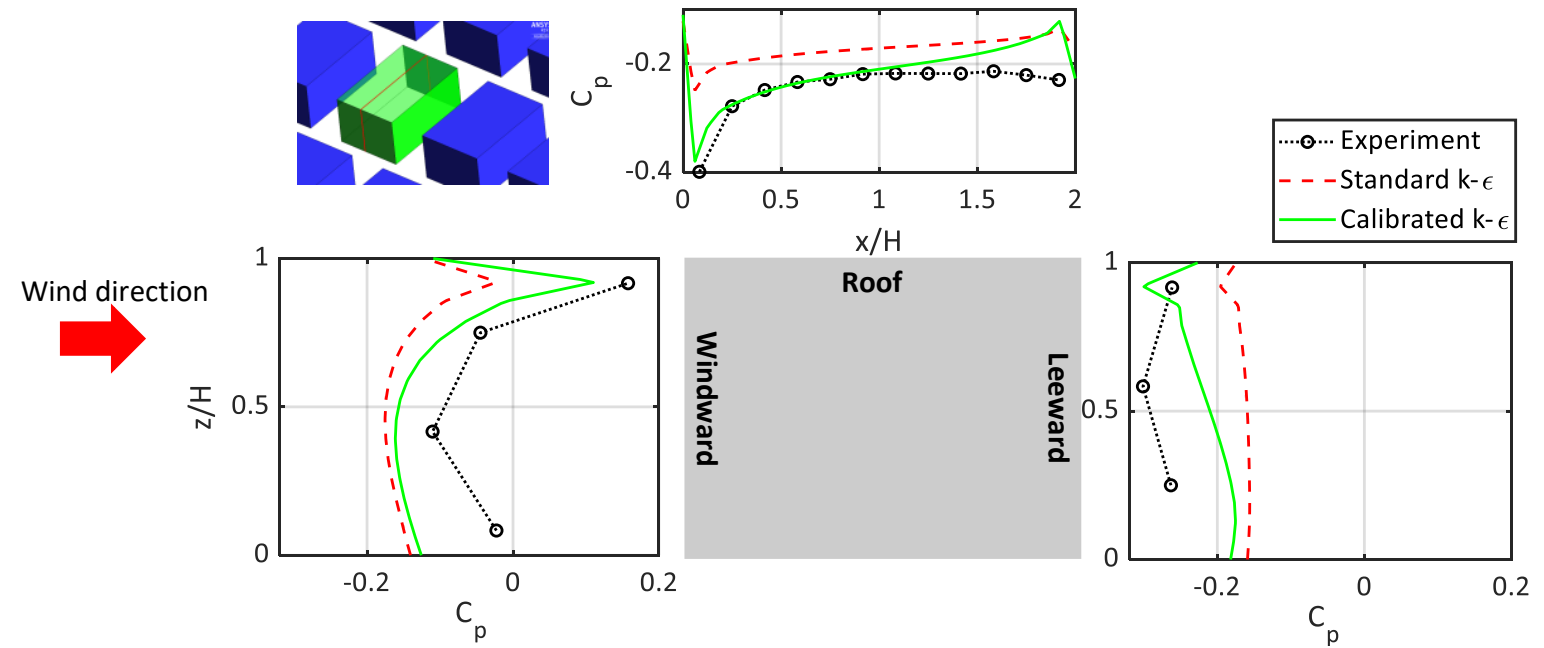

Figure 7 Variation of the surface wind pressure coefficient over building surfaces against the wind angle of $0^{\circ}$ for the sheltered building in highly-dense urban configuration (Case 3) 


\section{Discussion}

In the previous section, it was shown that the accuracy of RANS turbulence models can be improved for the three case studies by using the proposed calibration framework. In this section, the variation of the calibrated closure coefficients for above mentioned case studies are compared with similar studies in literature to understand the trend of the suitable closure coefficients for environmental and building studies. Only those case studies, which deal with the calibration of the $k-\varepsilon$ model are considered for comparison study as shown in Table 2. In the works presented by (Glover et al., 2011) and (Guillas et al., 2014), a Bayesian calibration method was utilized for a street canyon flow to calibrate the standard $k-\varepsilon$ model. The high quality data was acquired from a wind tunnel experiments by (Kastner-Klein et al., 2001) while distribution of TKE over a vertical plane between two blocks was considered as the focused output parameter. A total number of 620 and 150 CFD runs were performed in the calibration process by (Glover et al., 2011) and (Guillas et al., 2014), respectively. In another study by (lqbal and Chan, 2016), the closure coefficients of the standard $k-\varepsilon$ model were calibrated for prediction of the pedestrian wind environment around a group of high-rise cross-shaped buildings. They conducted two parametric studies using wind tunnel measurement and CFD simulation, and slightly retuned the coefficients proposed by (Glover et al., 2011) and (Guillas et al., 2014). In a similar studies by (Mittal et al., 2019a, 2019b), the wind amplification factor (as the focused output parameter) at pedestrian level around high-rise buildings with different shapes and corners geometries was studied. They used wind tunnel measurement data and conducted a sensitivity study and showed that the calibrated closure coefficients by (Shirzadi et al., 2017) are suitable for prediction of flow at the wake region behind the high rise building with different corners geometry and building shapes. 
Table 2 Details of closure coefficients calibration case studies in literature

\begin{tabular}{|c|c|c|c|c|c|}
\hline Authors & Case study & $\begin{array}{l}\text { Calibration } \\
\text { method }\end{array}$ & $\begin{array}{c}\text { Focused output } \\
\text { parameter }\end{array}$ & $\begin{array}{l}\text { High quality } \\
\text { data source }\end{array}$ & $\begin{array}{l}\text { No. samples } \\
\text { or iterations } \\
\text { for calibration }\end{array}$ \\
\hline $\begin{array}{l}\text { (Glover et } \\
\text { al., 2011) }\end{array}$ & $\begin{array}{l}\text { Street canyon flow } \\
\text { between two blocks }\end{array}$ & $\begin{array}{l}\text { Bayesian } \\
\text { calibration }\end{array}$ & $\begin{array}{l}\text { Vertical profile of } k \\
\text { between two buildings }\end{array}$ & $\begin{array}{c}\text { Wind tunnel } \\
\text { (Kastner-Klein et } \\
\text { al., 2001) }\end{array}$ & 620 \\
\hline $\begin{array}{l}\text { (Guillas et } \\
\text { al., 2014) }\end{array}$ & $\begin{array}{l}\text { Street canyon } \\
\text { flow between two } \\
\text { blocks }\end{array}$ & $\begin{array}{l}\text { Bayesian } \\
\text { calibration }\end{array}$ & $\begin{array}{l}\text { Vertical profile of } k \\
\text { between two buildings }\end{array}$ & $\begin{array}{c}\text { Wind tunnel } \\
\text { (Kastner-Klein et } \\
\text { al., 2001) }\end{array}$ & 150 \\
\hline $\begin{array}{c}\text { (lqbal and } \\
\text { Chan, 2016) }\end{array}$ & $\begin{array}{l}\text { Pedestrian wind } \\
\text { around a cross- } \\
\text { shaped high-rise } \\
\text { building }\end{array}$ & $\begin{array}{l}\text { Sensitivity } \\
\text { analysis }\end{array}$ & $\begin{array}{c}\text { Velocity magnitude } \\
\text { between buildings at the } \\
\text { pedestrian height }\end{array}$ & Wind tunnel & 2 \\
\hline $\begin{array}{l}\text { (Mittal } \\
\text { et al., } \\
\text { 2019a) }\end{array}$ & $\begin{array}{l}\text { Pedestrian wind } \\
\text { around high-rise } \\
\text { building different } \\
\text { shapes }\end{array}$ & $\begin{array}{l}\text { Sensitivity } \\
\text { analysis }\end{array}$ & Amplification factor & Wind tunnel & $\begin{array}{c}\text { Same } \\
\text { coefficients as } \\
\text { proposed by } \\
\text { (Shirzadi et al., } \\
2017 \text { ) }\end{array}$ \\
\hline $\begin{array}{l}\text { (Mittal } \\
\text { et al., } \\
\text { 2019b) }\end{array}$ & $\begin{array}{l}\text { Pedestrian wind } \\
\text { around high-rise } \\
\text { building with } \\
\text { different corner } \\
\text { shapes and } \\
\text { orientations }\end{array}$ & $\begin{array}{l}\text { Sensitivity } \\
\text { analysis }\end{array}$ & Amplification factor & Wind tunnel & $\begin{array}{l}\quad \text { Same } \\
\text { coefficients as } \\
\text { proposed by } \\
\text { (Shirzadi et al., } \\
2017 \text { ) }\end{array}$ \\
\hline
\end{tabular}

In Figure 8, the calibrated closure coefficients are shown for different case studies. In general, comparison of the calibrated coefficients shows similar trends for all case studies. In specific, $C_{\varepsilon 2}$, $C_{\mu}$, and $\sigma_{\varepsilon}$ are varied in a same direction among all studies. While the default value of $C_{\varepsilon 2}$ is 1.92 for the standard $k-\varepsilon$ model, the calibrated values for the street canyon (Glover et al., 2011; Guillas et al., 2014), a high-rise building with different shapes and corner geometries (Case 1 and (Mittal et al., 2019a, 2019b)), a cross-ventilated building in the sheltered condition (Case 2), and low-rise buildings in a highly-dense urban configuration (Case 3) are found to be higher than the default values, which are respectively $2.2,2.2,2.8,3.2$, and 3.2. For $C_{\mu}$, the same tendency can be observed; while the default value is 0.09 , the calibrated values for the street canyon flow (Glover et al., 2011; Guillas et al., 2014), and Case 1 to Case 3 are 0.12, 0.12, 0.15, 0.14, and 0.11 , respectively. Moreover, in all studies, the calibrated values of $\sigma_{\varepsilon}$ are significantly lower than the default value of 1.3 ; these values are $0.42,0.50,0.38,0.24$, and 0.35 for the street canyon, and Case 1 to Case 3, respectively. 


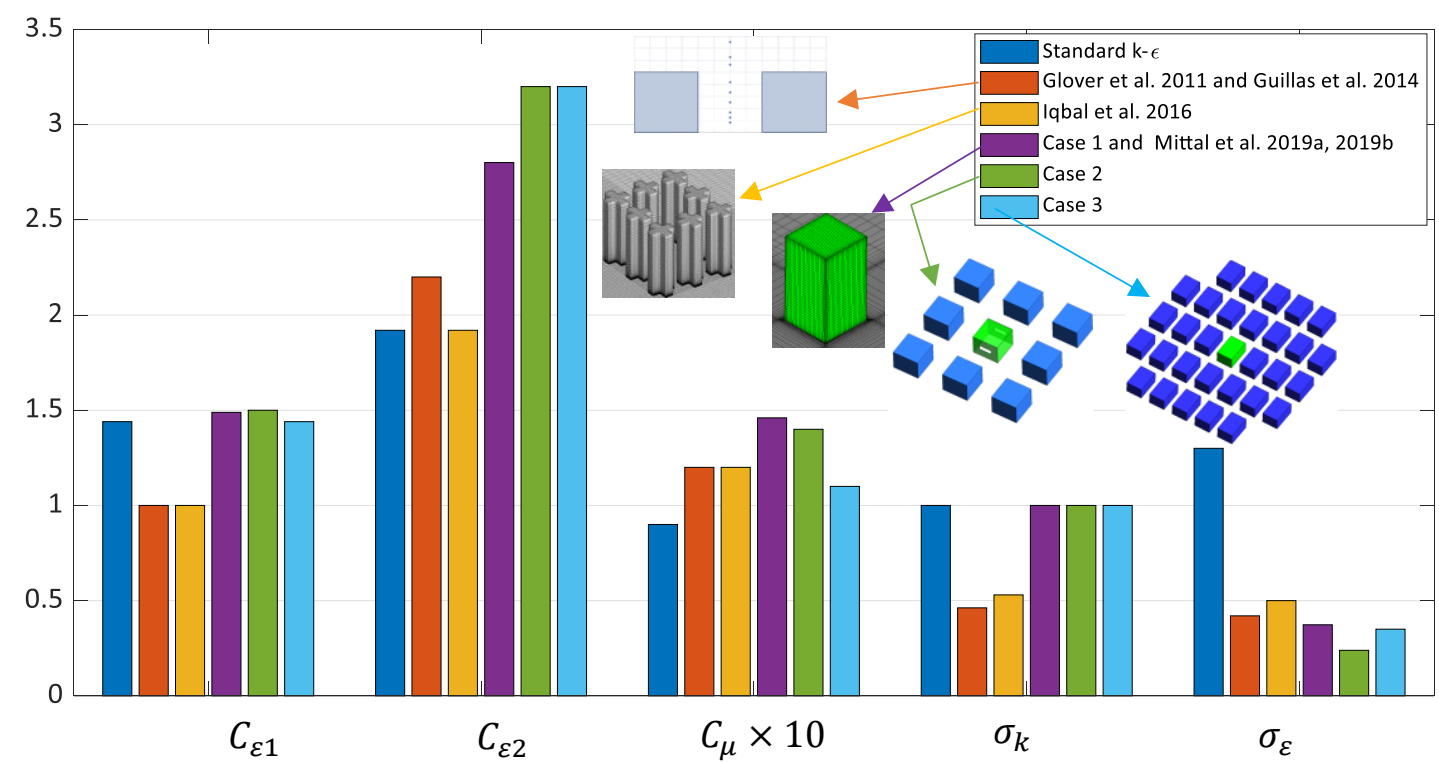

Figure 8 Comparison of the calibrated closure coefficients for different urban flows

A more detailed view on the variation of the closure coefficients during the calibration process for Case 1, Case 2, and Case 3 is shown in Figure 9(a) and (b). For Case 1 and Case 2, the mean value contours of the validation metrics, including FAC2, hit rate, and NMSE for velocity and TKE, are shown against different closure coefficients. For both cases, the highest values of FAC2 and hit rate are obtained in a range of $C_{\varepsilon 2} \geq 2.20$ and $C_{\mu} \geq 0.11$ while in this range, the NMSE is minimum. For Case 3 , the contours of the relative error in prediction of the surface-averaged wind pressure coefficient over the building walls are shown against different closure coefficients in Figure 9(c). The relative error is defined as below:

Relative error $=\left|\frac{\Delta C_{P}{ }^{\text {experiment }}-\Delta C_{P}{ }^{C F D}}{\Delta C_{P}{ }^{\text {experiment }}}\right| \times 100$

where $\Delta C_{P}$ is the surface pressure difference averaged over the windward and leeward façades. Surprisingly, a same trend similar to Case 1 and Case 2 can be observed while the relative error is minimum for $C_{\varepsilon 2} \geq 2.20$ and $C_{\mu} \geq 0.11$. 

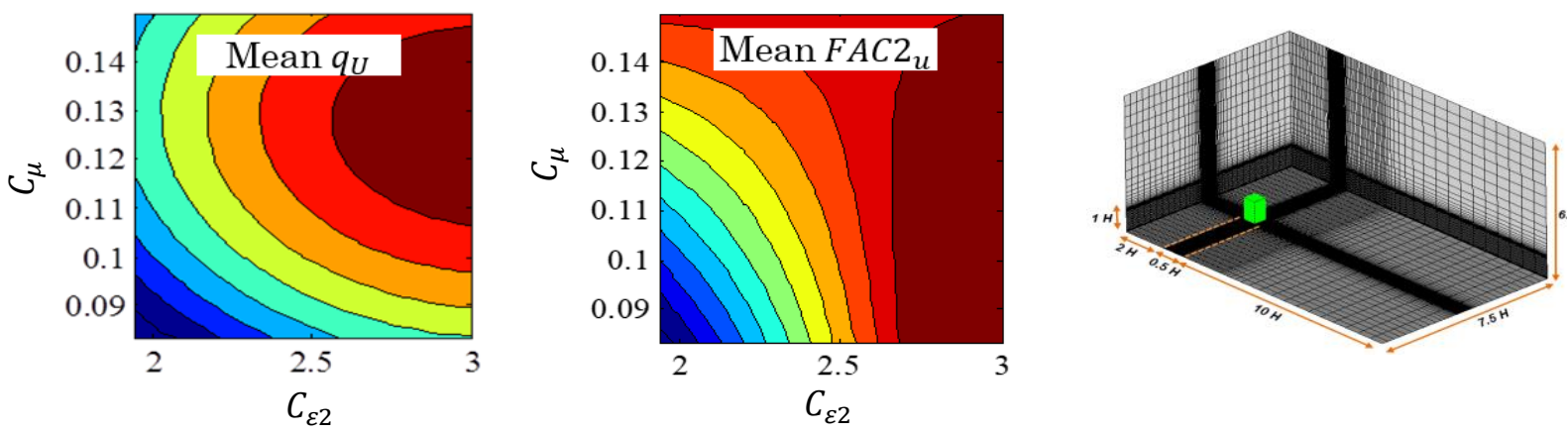

(a)
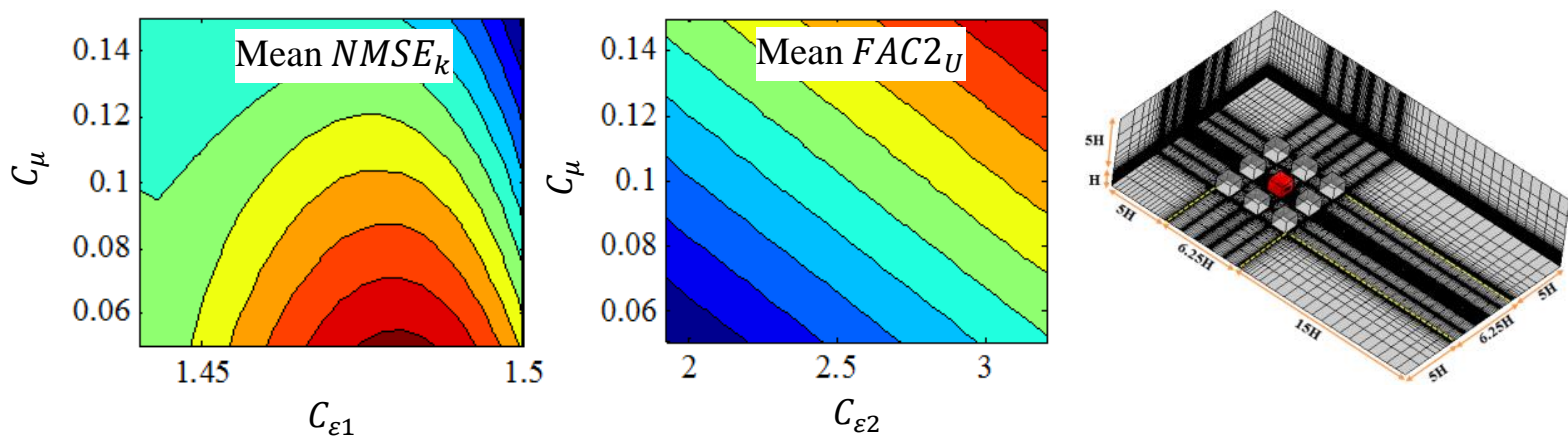

(b)
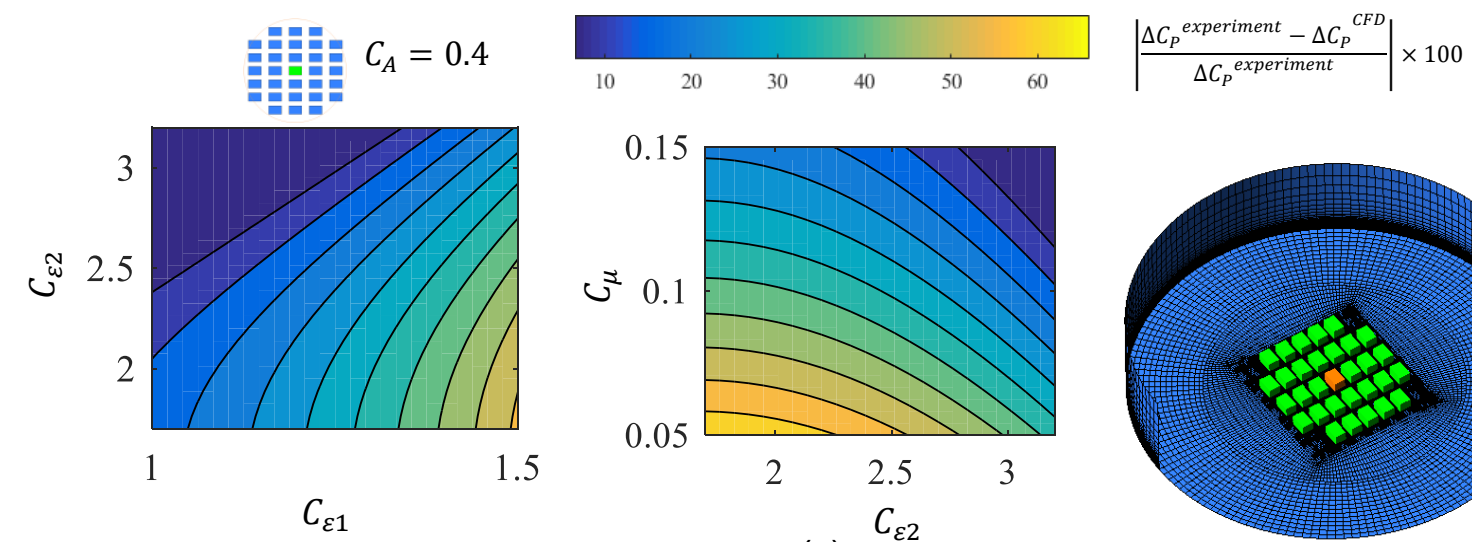

(c)

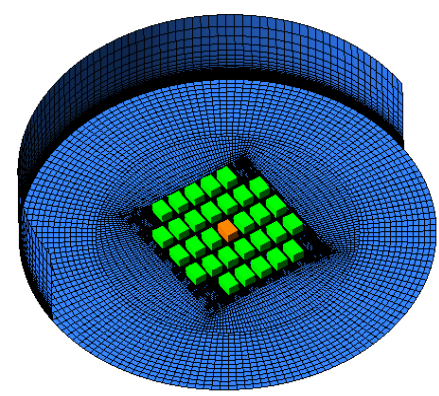

Figure 9 Contours of validation metrics and relative error during calibration process for (a) unsheltered high-rise building, (b) Case 2- sheltered cross-ventilated building, and (c) low-rise building in highly-dense urban area

The obtained values for the above-mentioned cases of urban flow can be initially analyzed by scrutinizing the transport equations for $k, \varepsilon$ and the turbulent viscosity equation (equations 2,3 , and 4). $C_{\varepsilon 2}$ appears in the transport equation for $\varepsilon$ as $-C_{\varepsilon 2} \rho \varepsilon$, which plays as a sink term (dissipation of dissipation) for $\varepsilon$ equation. Increasing $C_{\varepsilon 2}$ from its default value decreases $\varepsilon$ and consequently increases the turbulent viscosity in the turbulent viscosity equation $\mu_{t}=C_{\mu} \rho \frac{k^{2}}{\varepsilon}$. 
In a similar manner, when $C_{\mu}$ increases to higher values than its default one, the turbulent viscosity directly increases. Moreover, variation of $C_{\mu}$ indirectly changes the level of TKE through the production term in the transport equation for TKE as $P_{k}=\mu_{t} S^{2}=C_{\mu} \rho \frac{k^{2}}{\varepsilon} S^{2}$ in the standard $k-$ $\varepsilon$ model and $P_{k}=\mu_{t} S \Omega=C_{\mu} \rho \frac{k^{2}}{\varepsilon} S \Omega$ for the standard $k-\varepsilon$ model with LK modification. Hence, both closure coefficients cause an increase in the momentum diffusion and level of TKE around the building and within the adjacent cavities, which consequently improve the well-known momentum diffusion underestimation by SRANS models. $\sigma_{\varepsilon}$ appears in the $\varepsilon$ transport equation as the turbulent diffusion term $\frac{\partial}{x_{j}}\left[\left(\mu+\frac{\mu_{t}}{\sigma_{\varepsilon}}\right) \frac{\partial \varepsilon}{x_{j}}\right]$, which mathematically ensures a smooth solution of the $\varepsilon$ transport equation (Pope, 2001). The calibrated values of this closure coefficient in all case studies were obtained using the following relation between different closure coefficients and von Kármán constant $(\kappa)$ :

$$
\sigma_{\varepsilon}=\frac{\kappa^{2}}{C_{\mu}^{1 / 2}\left(C_{\varepsilon 2}-C_{\varepsilon 1}\right)}
$$

This relationship between the model constants satisfies the horizontal homogeneity of the ABL profile in the CFD models (Richards and Norris, 2011). Due to the nonlinear relation between the calibrated $C_{\varepsilon 2}, C_{\mu}$, and $\sigma_{\varepsilon}$, it is difficult to realize the contribution of $\varepsilon$ diffusion term on the overall $\varepsilon$, and thus turbulent viscosity distributions in the CFD model. Hence, more investigations are required for understanding the physical meaning of the calibrated $\sigma_{\varepsilon}$, as explained in section 2 , because $\varepsilon$ equation is completely empirical.

\section{Conclusions}

A framework for calibration of the RANS turbulence models was proposed in this study. The applicability of the calibration method was discussed for different urban flow case studies. It was shown that the well-known SRANS model underestimation of the turbulent kinetic energy and momentum diffusion around the buildings can be improved systematically with calibration of the closure coefficients using different sources of high-quality data, including field or wind tunnel measurements in addition to high-fidelity numerical models. The obtained values of the calibrated coefficients proved the plausibility of seeking optimum closure coefficients for urban flow problems.

Future work will focus on detailed investigation of the calibrated turbulence model in order to modify closure coefficients for a wider range of urban flows. Furthermore, application of other optimization methods will be investigated to reduce the computational cost of the calibration process. 


\section{Acknowledgments}

This work was supported by JSPS KAKENHI Grant Number JP20K14889. Faculty of engineering of the University of Nottingham is also acknowledged for the financial support.

\section{References}

Abbassi, Y., Ahmadikia, H., Baniasadi, E., 2019. Prediction of pollution dispersion under urban heat island circulation for different atmospheric stratification. Build. Environ. 106374.

Allegrini, J., Dorer, V., Carmeliet, J., 2015. Coupled CFD, radiation and building energy model for studying heat fluxes in an urban environment with generic building configurations. Sustain. Cities Soc. 19, 385-394. https://doi.org/https://doi.org/10.1016/j.scs.2015.07.009

Blocken, B., 2018. LES over RANS in building simulation for outdoor and indoor applications: A foregone conclusion? Build. Simul. 11, 821-870. https://doi.org/10.1007/s12273-018-04593

Blocken, B., 2014. 50 years of Computational Wind Engineering: Past, present and future. J. Wind Eng. Ind. Aerodyn. 129, 69-102. https://doi.org/https://doi.org/10.1016/j.jweia.2014.03.008

Blocken, B., Stathopoulos, T., Van Beeck, J., 2016. Pedestrian-level wind conditions around buildings: Review of wind-tunnel and CFD techniques and their accuracy for wind comfort assessment. Build. Environ. 100, 50-81.

Campolongo, F., Cariboni, J., Saltelli, A., 2007. An effective screening design for sensitivity analysis of large models. Environ. Model. Softw. 22, 1509-1518.

Charisi, S., Waszczuk, M., Thiis, T.K., 2019. Determining building-specific wind pressure coefficients to account for the microclimate in the calculation of air infiltration in buildings. Adv. Build. Energy Res. 1-22. https://doi.org/10.1080/17512549.2019.1596835

Cook, M.J., Zitzmann, T., Pfrommer, P., 2008. Dynamic thermal building analysis with CFD modelling radiation. J. Build. Perform. Simul. 1, 117-131. https://doi.org/10.1080/19401490802250421

Dejoan, A., Santiago, J.L., Pinelli, A., Martilli, A., 2007. 13.3 COMPARISON BETWEEN LES AND RANS COMPUTATIONS FOR THE STUDY OF CONTAMINANT DISPERSION IN THE MUST FIELD EXPERIMENT.

Detering, H.W., Etling, D., 1985. Application of the E- $\varepsilon$ turbulence model to the atmospheric boundary layer. Boundary-Layer Meteorol. 33, 113-133.

Duynkerke, P.G., 1988. Application of the E- $\varepsilon$ turbulence closure model to the neutral and stable atmospheric boundary layer. J. Atmos. Sci. 45, 865-880. 
Fadl, M.S., Karadelis, J., 2013. CFD simulation for wind comfort and safety in urban area: A case study of Coventry University central campus. Int. J. Archit. Eng. Constr. 2, 131-143.

Fan, Y., Ito, K., 2012. Energy consumption analysis intended for real office space with energy recovery ventilator by integrating BES and CFD approaches. Build. Environ. 52, 57-67.

Franke, J., Hellsten, A., Schlünzen, H., Carissimo, B., 2007. Best Practice Guideline for the CFD Simulation of Flows in the Urban Environment. COST Action 732: Quality Assurance and Improvement of Microscale Meteorological Models. Hamburg, Ger.

Gimenez, J.M., Bre, F., 2019. Optimization of RANS turbulence models using genetic algorithms to improve the prediction of wind pressure coefficients on low-rise buildings. J. Wind Eng. Ind. Aerodyn. 193, 103978. https://doi.org/https://doi.org/10.1016/j.jweia.2019.103978

Glover, N., Guillas, S., Malki-Epshtein, L., 2011. Statistical calibration of CFD modelling for street canyon flows, in: Proceedings of Building Simulation 2011: 12th Conference of International Building Performance Simulation Association. International Building Performance Simulation Association (IBSPA), pp. 1513-1520.

Gonzalez Olivardia, F.G., Zhang, Q., Matsuo, T., Shimadera, H., Kondo, A., 2019. Analysis of Pollutant Dispersion in a Realistic Urban Street Canyon Using Coupled CFD and Chemical Reaction Modeling. Atmosphere (Basel). 10, 479.

Guillas, S., Glover, N., Malki-Epshtein, L., 2014. Bayesian calibration of the constants of the $k-\varepsilon$ turbulence model for a CFD model of street canyon flow. Comput. Methods Appl. Mech. Eng. 279, 536-553.

Haghighat, F., Mirzaei, P.A., 2011. Impact of non-uniform urban surface temperature on pollution dispersion in urban areas, in: Building Simulation. Springer, pp. 227-244.

Hien, W.N., Ignatius, M., Eliza, A., Jusuf, S.K., Samsudin, R., 2012. Comparison of STEVE and ENVI-met as temperature prediction models for Singapore context. Int. J. Sustain. Build. Technol. Urban Dev. 3, 197-209. https://doi.org/10.1080/2093761X.2012.720224

Ikegaya, N., Okaze, T., Kikumoto, H., Imano, M., Ono, H., Tominaga, Y., 2019. Effect of the numerical viscosity on reproduction of mean and turbulent flow fields in the case of a 1:1: 2 single block model. J. Wind Eng. Ind. Aerodyn. 191, 279-296.

lqbal, Q.M.Z., Chan, A.L.S., 2016. Pedestrian level wind environment assessment around group of high-rise cross-shaped buildings: Effect of building shape, separation and orientation. Build. Environ. 101, 45-63.

Jiru, T.E., Bitsuamlak, G.T., 2010. Application of CFD in Modelling Wind-Induced Natural Ventilation of Buildings - A Review. Int. J. Vent. 9, 131-147. 
https://doi.org/10.1080/14733315.2010.11683875

Kastner-Klein, P., Fedorovich, E., Rotach, M.W., 2001. A wind tunnel study of organised and turbulent air motions in urban street canyons. J. Wind Eng. Ind. Aerodyn. 89, 849-861.

Kato, M., Launder, B.E., 1993. The modelling of turbulent flow around stationary and vibrating square cylinders. Turbul. Shear Flow 1, 10.4. 1-10.4. 6.

Kawamoto, Y., 2016. Effect of Urbanization on the Urban Heat Island in Fukuoka-Kitakyushu Metropolitan Area, Japan. Procedia Eng. 169, 224-231.

Kim, J., Moin, P., Moser, R., 1987. Turbulence statistics in fully developed channel flow at low Reynolds number. J. Fluid Mech. 177, 133-166.

Koch, P.N., Yang, R.-J., Gu, L., 2004. Design for six sigma through robust optimization. Struct. Multidiscip. Optim. 26, 235-248.

Kurabuchi, T., Ohba, M., Arashiguchi, A., Iwabuchi, T., 2000. Numerical study of airflow structure of a cross ventilated model building. Air Distrib. rooms Vent. Heal. Sustain. Environ. 2, 313.

Launder, B.E., Spalding, D.B., 1974. The numerical computation of turbulent flows. Comput. Methods Appl. Mech. Eng. 3, 269-289.

Liu, J., Niu, J., 2016. CFD simulation of the wind environment around an isolated high-rise building: An evaluation of SRANS, LES and DES models. Build. Environ. 96, 91-106. https://doi.org/https://doi.org/10.1016/j.buildenv.2015.11.007

Longo, R., Fürst, M., Bellemans, A., Ferrarotti, M., Derudi, M., Parente, A., 2019. CFD dispersion study based on a variable Schmidt formulation for flows around different configurations of ground-mounted buildings. Build. Environ. 154, 336-347.

Luo, K., Yu, H., Dai, Z., Fang, M., Fan, J., 2016. CFD simulations of flow and dust dispersion in a realistic urban area. Eng. Appl. Comput. Fluid Mech. 10, 228-242. https://doi.org/10.1080/19942060.2016.1150205

Malys, L., Musy, M., Inard, C., 2015. Microclimate and building energy consumption: study of different coupling methods. Adv. Build. Energy Res. 9, 151-174. https://doi.org/10.1080/17512549.2015.1043643

Menter, F.R., 1994. Two-equation eddy-viscosity turbulence models for engineering applications. AIAA J. 32, 1598-1605.

Mirzaei, P.A., Haghighat, F., 2011. Pollution removal effectiveness of the pedestrian ventilation system. J. Wind Eng. Ind. Aerodyn. 99, 46-58.

Mirzaei, P.A., Olsthoorn, D., Torjan, M., Haghighat, F., 2015. Urban neighborhood characteristics influence on a building indoor environment. Sustain. Cities Soc. 19, 403- 
413. https://doi.org/https://doi.org/10.1016/j.scs.2015.07.008

Mittal, H., Sharma, A., Gairola, A., 2019a. Numerical simulation of pedestrian level wind conditions: effect of building shape and orientation. Environ. Fluid Mech. 1-26.

Mittal, H., Sharma, A., Gairola, A., 2019b. Numerical simulation of pedestrian level wind flow around buildings: Effect of corner modification and orientation. J. Build. Eng. 22, 314-326. https://doi.org/https://doi.org/10.1016/j.jobe.2018.12.014

Mochida, A., Tominaga, Y., Murakami, S., Yoshie, R., Ishihara, T., Ooka, R., 2002. Comparison of various ke models and DSM applied to flow around a high-rise building. Wind Struct. 5, 227-244.

Mochida, A., Tominaga, Y., Yoshie, R., 2006a. AlJ guideline for practical applications of CFD to wind environment around buildings, in: 4th International Symposium on Computational Wind Engineering (CWE2006).

Mochida, A., Yoshino, H., Miyauchi, S., Mitamura, T., 2006b. Total analysis of cooling effects of cross-ventilation affected by microclimate around a building. Sol. Energy 80, 371-382.

Montgomery, D.C., Runger, G.C., Hubele, N.F., 2009. Engineering statistics. John Wiley \& Sons.

Murakami, S., Mochida, A., Hayashi, Y., 1990. examining the $\mathrm{k}-\epsilon$ model by means of a wind tunnel test and large-eddy simulation of the turbulence structure around a cube. J. Wind Eng. Ind. Aerodyn. 35, 87-100.

Murakami, S., Ooka, R., Kato, S., lizuka, S., Mochida, A., 1996. Numerical prediction of flow around a building with various turbulence models: Comparison of $\{k a p p a\}-\{v a r$ epsilon $\}$ EVM, ASM, DSM, and LES wind tunnel tests. American Society of Heating, Refrigerating and Air-Conditioning Engineers ....

Okaze, T., Kikumoto, H., Ono, H., Imano, M., Hasama, T., Kishida, T., Nakao, K., Ikegaya, N., Tabata, Y., Tominaga, Y., 2017. Large-eddy simulations of flow around a high-rise buildingvalidation and sensitivity analysis on turbulent statistics, in: Proceedings of the 7th European and African Conference on Wind Engineering, Liege, Belgium. pp. 3-6.

Pope, S.B., 2001. Turbulent flows.

Priyadarsini, R., 2009. Urban Heat Island and its Impact on Building Energy Consumption. Adv. Build. Energy Res. 3, 261-270. https://doi.org/10.3763/aber.2009.0310

Quan, Y., Tamura, Y., Matsui, M., Cao, S., Yoshida, A., Xu, S., 2007. Interference effect of a surrounding building group on wind loads on flat roof of low-rise building: Part I, Distribution of local wind pressure coefficient. Wind Eng. JAWE 32, 211-212.

Richards, P.J., Norris, S.E., 2011. Appropriate boundary conditions for computational wind 
engineering models revisited. J. Wind Eng. Ind. Aerodyn. 99, 257-266.

Rogers, M.M., Moser, R.D., 1994. Direct simulation of a self-similar turbulent mixing layer. Phys. Fluids 6, 903-923.

Schatzmann, M., 2010. COST 732 model evaluation case studies: approach and results. Meteorological Inst.

Schittkowski, K., 2006. NLPQLP: A Fortran implementation of a sequential quadratic programming algorithm with distributed and non-monotone line search-user's guide.

Serteser, N., Karadag, I., 2018. Design for improving pedestrian wind comfort: a case study on a courtyard around a tall building. Archit. Sci. Rev. 61, 492-499. https://doi.org/10.1080/00038628.2018.1492899

Shao, J., Liu, J., Zhao, J., 2012. Evaluation of various non-linear k-ع models for predicting wind flow around an isolated high-rise building within the surface boundary layer. Build. Environ. $57,145-155$.

Shih, T.-H., Liou, W.W., Shabbir, A., Yang, Z., Zhu, J., 1995. A new k- $\epsilon$ eddy viscosity model for high reynolds number turbulent flows. Comput. Fluids 24, 227-238.

Shirasawa, T., Mochida, A., Tominaga, Y., YOSHINO, H., 2006. Evaluation of turbulent time scale of linear revised K- $\varepsilon$ models based on LES data. JWE 日本風工学研究会誌 125-128.

Shirzadi, M., Mirzaei, P.A., Naghashzadegan, M., 2017. Improvement of k-epsilon turbulence model for CFD simulation of atmospheric boundary layer around a high-rise building using stochastic optimization and Monte Carlo Sampling technique. J. Wind Eng. Ind. Aerodyn. 171. https://doi.org/10.1016/j.jweia.2017.10.005

Shirzadi, M., Mirzaei, P.A., Naghashzadegan, M., Tominaga, Y., 2018a. Modelling enhancement of cross-ventilation in sheltered buildings using stochastic optimization. Int. J. Heat Mass Transf. 118. https://doi.org/10.1016/j.ijheatmasstransfer.2017.10.107

Shirzadi, M., Naghashzadegan, M., A. Mirzaei, P., 2018b. Improving the CFD modelling of cross-ventilation in highly-packed urban areas. Sustain. Cities Soc. 37. https://doi.org/10.1016/j.scs.2017.11.020

Tavoularis, S., Karnik, U., 1989. Further experiments on the evolution of turbulent stresses and scales in uniformly sheared turbulence. J. Fluid Mech. 204, 457-478.

Tolias, I.C., Koutsourakis, N., Hertwig, D., Efthimiou, G.C., Venetsanos, A.G., Bartzis, J.G., 2018. Large Eddy Simulation study on the structure of turbulent flow in a complex city. J. Wind Eng. Ind. Aerodyn. https://doi.org/10.1016/j.jweia.2018.03.017

Tominaga, Y., 2015. Flow around a high-rise building using steady and unsteady RANS CFD: Effect of large-scale fluctuations on the velocity statistics. J. Wind Eng. Ind. Aerodyn. 142, 
93-103.

Tominaga, Y., Blocken, B., 2015. Wind tunnel experiments on cross-ventilation flow of a generic building with contaminant dispersion in unsheltered and sheltered conditions. Build. Environ. 92, 452-461.

Tominaga, Y., Mochida, A., Murakami, S., Sawaki, S., 2008a. Comparison of various revised k$\varepsilon$ models and LES applied to flow around a high-rise building model with 1:1:2 shape placed within the surface boundary layer. J. Wind Eng. Ind. Aerodyn. 96, 389-411.

Tominaga, Y., Mochida, A., Yoshie, R., Kataoka, H., Nozu, T., Yoshikawa, M., Shirasawa, T., 2008b. AlJ guidelines for practical applications of CFD to pedestrian wind environment around buildings. J. Wind Eng. Ind. Aerodyn. 96, 1749-1761.

Tominaga, Y., Stathopoulos, T., 2011. CFD modeling of pollution dispersion in a street canyon: Comparison between LES and RANS. J. Wind Eng. Ind. Aerodyn. 99, 340-348.

Tominaga, Y., Stathopoulos, T., 2010. Numerical simulation of dispersion around an isolated cubic building: model evaluation of RANS and LES. Build. Environ. 45, 2231-2239.

Tsang, C.W., Kwok, K.C.S., Hitchcock, P.A., 2012. Wind tunnel study of pedestrian level wind environment around tall buildings: Effects of building dimensions, separation and podium. Build. Environ. 49, 167-181.

Tsuchiya, M., Murakami, S., Mochida, A., Kondo, K., Ishida, Y., 1997. Development of a new k$\varepsilon$ model for flow and pressure fields around bluff body. J. Wind Eng. Ind. Aerodyn. 67, 169182.

Wang, Xiaoxia, Zou, C., Wang, Xiaofei, Liu, X., 2019. Impact of vehicular exhaust emissions on pedestrian health under different traffic structures and wind speeds. Hum. Ecol. Risk Assess. An Int. J. 1-17. https://doi.org/10.1080/10807039.2019.1597624

Wilcox, D.C., 1998. Turbulence modeling for CFD. La Canada, California: DCW Industries. Inc 5354, 124-128.

Yakhot, V., Orszag, S.A., 1986. Renormalization-group analysis of turbulence. Phys. Rev. Lett. $57,1722$.

Yakhot, V., Orszag, S.A., Thangam, S., Gatski, T.B., Speziale, C.G., 1992. Development of turbulence models for shear flows by a double expansion technique. Phys. Fluids A Fluid Dyn. 4, 1510-1520.

Yoshie, R., Jiang, G., Shirasawa, T., Chung, J., 2011. CFD simulations of gas dispersion around high-rise building in non-isothermal boundary layer. J. Wind Eng. Ind. Aerodyn. 99, 279-288.

Yoshie, R., Mochida, A., Tominaga, Y., Kataoka, H., Harimoto, K., Nozu, T., Shirasawa, T., 
2007. Cooperative project for CFD prediction of pedestrian wind environment in the Architectural Institute of Japan. J. Wind Eng. Ind. Aerodyn. 95, 1551-1578.

Yu, H., Thé, J., 2016. Validation and optimization of SST k- $\omega$ turbulence model for pollutant dispersion within a building array. Atmos. Environ. 145, 225-238.

https://doi.org/https://doi.org/10.1016/j.atmosenv.2016.09.043

Zhai, Z., Chen, Q., Haves, P., Klems, J.H., 2002. On approaches to couple energy simulation and computational fluid dynamics programs. Build. Environ. 37, 857-864.

Zhang, R., Mirzaei, P.A., Jones, B., 2018. Development of a dynamic external CFD and BES coupling framework for application of urban neighbourhoods energy modelling. Build. Environ. 146, 37-49. 